\title{
GMR
}

\section{Influence of different fluid resuscitation techniques on the number of myeloid-derived suppressor cells in rats}

\author{
Z.J. Wang ${ }^{1}$ H.X. Wang ${ }^{2}$, L. Li ${ }^{1}$, L. Wang ${ }^{1}$ and H.H. Dou ${ }^{1}$ \\ ${ }^{1}$ Department of Emergency Surgery, \\ The First Affiliated Hospital of Bengbu medical College, Bengbu, Anhui, \\ China \\ ${ }^{2}$ Jiaozuo Coal Industry (Group) Co., \\ Ltd. Central Hospital Department of orthopedics, Jiaozuo, Henan, China \\ Corresponding author: Z.J. Wang \\ E-mail: wzhnjie@163.com
}

Genet. Mol. Res. 15 (2): gmr.15028181

Received December 2, 2015

Accepted January 18, 2016

Published April 27, 2016

DOI http://dx.doi.org/10.4238/gmr.15028181

\begin{abstract}
We investigated the influence of different fluid resuscitation techniques on the number of myeloid-derived suppressor cells (MDSCs) in rats. Seventy-two healthy Sprague-Dawley rats were randomly divided into groups that received sham operation (Sham group), hypertonic saline (HRS group), lactated ringer's solution (LRS group), or crystalloid solution (LCRS group). Six rats from each group were sacrificed by cervical dislocation at 12,24 , and $48 \mathrm{~h}$ after resuscitation. The spleens were harvested under sterile conditions and spleen cell suspension was prepared. The number of MDSCs was detected using flow cytometry. The number of MDSCs in the Sham group did not differ significantly among the different time points. Compared with the Sham group, the number of MDSCs after the use of the different fluid resuscitation techniques increased to varying extents and the differences among the groups were significant. The number of MDSCs in the HRS group was much lower than that of the LRS and
\end{abstract}


LCRS groups at both 24 and $48 \mathrm{~h}(\mathrm{P}<0.05)$. At $12 \mathrm{~h}$, the number of MDSCs in the HRS group was significantly lower than that of the LRS group $(\mathrm{P}<0.05)$. The differences between the HRS and LCRS groups were not statistically significant. Shortly after hemorrhagic shock resuscitation, the immune function of rats was suppressed to a varying extent and was gradually restored over time. Resuscitation with HRS alleviated the immunosuppression at the early stage after shock.

Key words: Rats; Hemorrhagic shock; Fluid resuscitation; MDSCs; Myeloid-derived suppressor cells

\section{INTRODUCTION}

Hemorrhagic shock is a common critical clinical illness, and fluid resuscitation is the countermeasure to address this. Although the short-term survival of patients after resuscitation increases, the long-term mortality is still high, which may be attributed to the resulting immunological stress and inflammatory response. Different fluid resuscitation techniques may have different effects on the immune response after hemorrhagic shock (Gao et al., 2009; Gao et al., 2013; Villarroel et al., 2013; Cheng et al., 2014). Myeloid cells, first discovered in tumor patients, play a negative regulatory role in the immune system and have recently acquired the collective term myeloid-derived suppressor cells (MDSCs)(Krystal et al., 2007). Consisting of immature granulocyte and monocytes, MDSCs express differentiation antigen His 48 and CD11b/c in rats. Recent studies have shown that traumatic hemorrhagic shock can either directly or indirectly activate the proliferation of MDSCs (Cuenca et al., 2011; Lu et al., 2013). In the present study, we built a rat model of traumatic hemorrhagic shock, to observe the influence of different fluid resuscitation techniques on the number of MDSCs in the rat spleen following traumatic hemorrhagic shock. A fluid resuscitation technique that optimally reduced the immunosuppression after hemorrhagic shock was identified.

\section{MATERIAL AND METHODS}

Seventy-two healthy Sprague-Dawley male rats weighing 250-300 g, were provided by the Experimental Animal Center of Bengbu Medical College. They were equally and randomly divided into four groups: sham operation group (Sham group), hypertonic saline group (HRS group), lactated ringer's solution group (LRS group) and crystalloid solution group (LCRS group).

\section{Construction of rat model of hemorrhagic shock}

The rat model of hemorrhagic shock was constructed based on Chaudry's method (Villarroel et al., 2013) with some modifications. The rats were anesthetized by intraperitoneal injection of pentobarbital sodium $(40 \mathrm{mg} / \mathrm{kg})$ and immobilized on a $25^{\circ} \mathrm{C}$ heating plate using $500 \mathrm{U} / \mathrm{kg}$ heparin anticoagulation. Skin preparation was performed on the bilateral inguinal region and a 1:1 povidone-iodine solution was applied for disinfection three times. The skin in the left inguinal region was cut open to separate and expose the femoral vein and femoral artery. No. 24 and No. 22 cannula needles were inserted, respectively. A micro-infusion 
pump and Medlab system were connected (the heparin lock flush solution used in blood pressure measurement system was prepared by adding $3750 \mathrm{U}$ heparin sodium in $500 \mathrm{~mL}$ normal saline). The right femoral artery was separated and a No. 22 cannula needle was inserted to draw the blood, which was then stored in sterile bottles with heparin anticoagulation. Mean arterial pressure (MAP) was decreased to $40 \mathrm{mmHg}$ within $10 \mathrm{~min}$ and maintained at that level for $30 \mathrm{~min}$ to induce shock. Then, fluid resuscitation was given, using the micro-infusion pump via the femoral vein, increasing MAP to $60 \mathrm{mmHg}$ within $20 \mathrm{~min}$. Autologous blood transfusion was performed at the volume of $1 / 3$ of the blood loss, which was followed by the infusion of different solutions to raise MAP to $80 \mathrm{mmHg}$. After MAP had been maintained at $80 \mathrm{mmHg}$ for $1 \mathrm{~h}$, the indwelling needles in the femoral artery and femoral vein were removed. The femoral vein and femoral artery were ligated and sutured. The rats were sent back to their cages and reared at a temperature of $25^{\circ} \mathrm{C}$.

For the Sham group, only catheterization of the femoral artery and femoral vein was performed, to monitor the MAP without induction of hemorrhagic shock. The rats were sent back to their cages and reared at a temperature of $25^{\circ} \mathrm{C}$.

\section{Isolation and detection of MDSCs}

Six rats from each of the four groups; the Sham group and the three experimental shock groups, were sacrificed by cervical dislocation at 12,24 , and $48 \mathrm{~h}$, respectively. The spleens were harvested under sterile conditions, converted cell suspension, and centrifuged with the supernatant discarded. A red blood cell lysis buffer was added with proper mixing, and the cells were centrifuged and the supernatant was discarded. After washing with PBS buffer twice and resuspension, rat anti$\mathrm{CDllb} / \mathrm{c}$ antibodies and anti-His 48 antibodies were added and incubated in the dark for $30 \mathrm{~min}$. The cells were then centrifuged and the supernatant was discarded. Before flow cytometry, the cells were washed twice with PBS buffer and resuspended in an appropriate amount of PBS.

\section{Statistical analysis}

All data are reported as means \pm standard deviation. A one-way ANOVA was employed for intergroup comparison and all statistical analyses were performed using SPSS 17.0. P < 0.05 indicated a statistically significant difference.

\section{RESULTS}

\section{Comparison of baseline data of rats in each group before modeling}

No obvious differences existed in body weight or in MAP of the rats between the different groups before modeling according to the one-way ANOVA $(\mathrm{P}>0.05)$; therefore, the groups were comparable (Table 1).

\section{Comparison of number of MDSCs in spleens of rats from different groups}

The number of MDSCs was detected in the spleen, using flow cytometry (Figure 1). The ratio shown the right upper quadrant in Figure 1 is the ratio of cells positive for His 48 compared to those positive for CD11b/c. Cells positive for both His 48 and CD11b/c were defined as MDSCs. 
Table 1. Comparison of body weight and MAP of rats in each group before modeling (means $\pm \mathrm{SD}$ ).

\begin{tabular}{l|c|c|c}
\hline Group & $\mathrm{N}$ & Body weight $(\mathrm{g})$ & MAP $(\mathrm{mmHg})$ \\
\hline Sham group & 18 & $266.03 \pm 15.62$ & $128.68 \pm 3.73$ \\
\hline HRS group & 18 & $270.27 \pm 10.83$ & $126.18 \pm 1.88$ \\
\hline LRS group & 18 & $273.27 \pm 13.48$ & $126.42 \pm 3.17$ \\
\hline LCRS group & 18 & $266.46 \pm 17.43$ & $124.67 \pm 2.20$ \\
\hline F value & - & 0.332 & 2.039 \\
\hline P value & - & 0.686 & 0.141
\end{tabular}

$\mathrm{P}>0.05$ indicated no statistically significant difference, whereas $\mathrm{P}<0.05$ indicated statistically significant difference.

Cell detections were made at different time points (Table 2, Figure 2), and the results indicated that the number of MDSCs in the Sham group did not vary significantly among the three time points after modeling. Compared to the Sham group, the number of MDSCs in the HRS, LRS, and LCRS groups increased dramatically. The number of MDSCs in the HRS group was much lower than those in the LRS and LCRS groups at 24 and $48 \mathrm{~h}$, respectively $(\mathrm{P}<0.05)$. The number of MDSCs in the HRS group at $12 \mathrm{~h}$ was also obviously lower than that of the LRS group $(\mathrm{P}<0.05)$; however, no significant difference was found compared to the LCRS group.

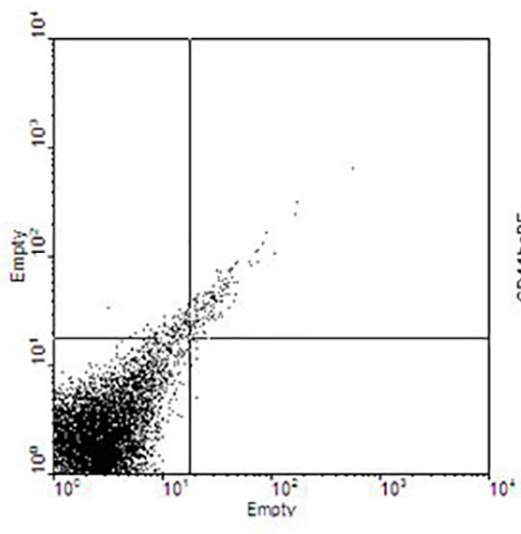

A

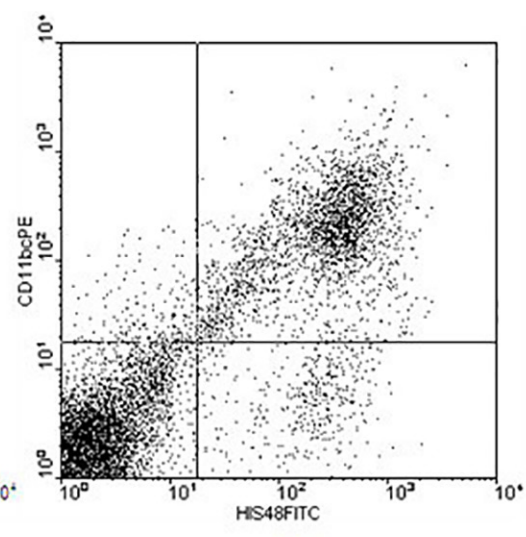

B

Figure 1. Results of flow cytometry. With A as reference, the right upper quadrant in B represents the doubleantibody positive area, or the proportion of MDSCs.

Table 2. Comparison of the number of MDSCs in the spleen of rats from different groups at three time points (means $\pm \mathrm{SD})$.

\begin{tabular}{l|c|c|c}
\hline Group & $12 \mathrm{~h}$ & $24 \mathrm{~h}$ & $48 \mathrm{~h}$ \\
\hline Sham group $(\mathrm{N}=18)$ & $5.58 \pm 1.31$ & $6.44 \pm 1.54$ & $5.24 \pm 1.15$ \\
\hline HRS group $(\mathrm{N}=18)$ & $9.60 \pm 1.72^{*}$ & $14.69 \pm 2.21^{*}$ & $11.50 \pm 1.37^{*}$ \\
\hline LRS group $(\mathrm{N}=18)$ & $13.41 \pm 2.05^{* \#}$ & $24.33 \pm 3.03^{* \#}$ & $15.17 \pm 2.13^{* \#}$ \\
\hline LCRS group $(\mathrm{N}=18)$ & $12.25 \pm 2.40^{*}$ & $20.32 \pm 2.31^{* \#}$ & $17.64 \pm 1.98^{* *}$ \\
\hline F value & 19.71 & 66.18 & 59.70 \\
\hline P value & 0.000 & 0.000 & 0.000 \\
\hline
\end{tabular}

${ }^{*} \mathrm{P}<0.05$ compared with the Sham group; ${ }^{*} \mathrm{P}<0.05$ compared with the HRS group. 


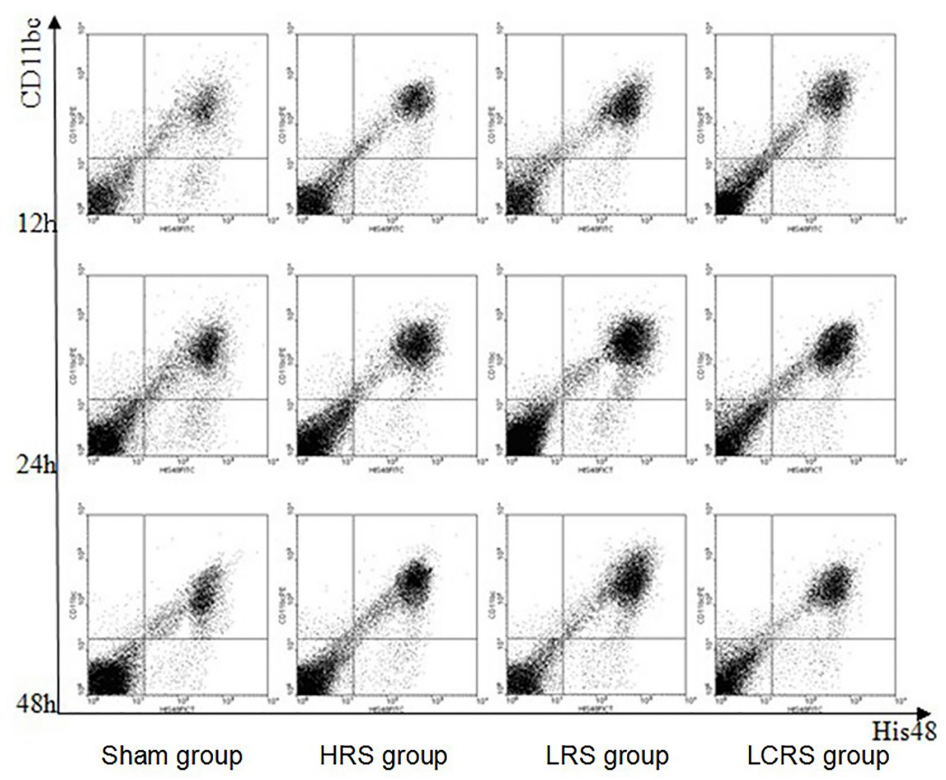

Figure 2. Results of flow cytometry in different groups at different time points.

\section{DISCUSSION}

Traumatic hemorrhagic shock can cause death within a few hours after trauma, and effective fluid resuscitation is usually adopted as the salvage therapy. Apart from circulatory disturbance, traumatic hemorrhagic shock manifests itself in severe immune system disorders and inflammatory response, which are nearly as detrimental as hypovolemia. These responses can lead to multiple organ failure, sepsis, and even death. MDSCs are a heterogeneous group of myeloid cells that suppress $\mathrm{T}$ cell activity, including macrophages, granulocytes, and dendritic cells typically at the immature or early differentiation stage (Krystal et al., 2007). Exerting an immunosuppressive effect (Serafini et al., 2008; Yang et al., 2015), MDSCs can be activated into extensive proliferation by various cytokines (Delano et al., 2007; Schneider et al., 2006). MDSCs were first discovered in tumors where they were found to be involved in the mechanism of tumor immune escape. In recent years, the interest in MDSCs has been extended to infections and traumatic hemorrhagic shock (Cuenca et al., 2011; Darcy et al., 2014; Köstlin et al., 2014; Yao et al., 2015).

Hypovolemia and microcirculatory disturbance are the pathological bases of hemorrhagic shock, and the concurrent inflammation and immune disorders exert an important influence on the development of shock. MDSCs fulfill the immunosuppressive functions through multiple mechanisms. The number of MDSCs in the spleen increases dramatically after traumatic stress, thereby inhibiting the $\mathrm{T}$ cell activity and inducing sepsis. Accumulation of MDSCs is closely related to the occurrence of sepsis. Therefore, finding ways to decrease MDSCs and alleviating the immunosuppression are major concerns in fluid resuscitation.

Hypertonic salt solutions have, in recent years, more frequently been applied for antishock purposes. In 1980, Velasco first reported the resuscitation of severe hemorrhagic shock in dogs using $7.5 \%$ sodium chloride (Velasco et al., 1980). After that, many researches focused 
on the use of hypertonic salt solutions for early resuscitation. Animal experiments have shown that hypertonic salt solutions influence the hemodynamics through selective dilation of small arteries that lead to capillaries, supplying oxygen to important organs. Moreover, hypertonic salt solutions are also superior to crystalloid or colloid solutions, in terms of immunomodulatory effect (Chiara et al., 2003; Junger et al., 2012; Kim et al., 2012).

As shown in our comparative study, the number of MDSCs in the spleen of rats increased to varying extents after hemorrhagic shock resuscitation, which was followed by a decline of MDSCs. The HRS group showed the smallest change in MDSCs and the differences were significant compared with the LCRS and LRS groups. This indicates that the immune function was suppressed after hemorrhagic shock and, thus, that HRS resuscitation had the least impact on the immune function. Therefore, HRS may be suitable for reducing immune-mediated inflammation and maintaining immune balance. Moreover, compared with the LCRS and LRS groups, the increase of MDSCs in the HRS group after resuscitation was considerably lower at all three time points. Hence, resuscitation with HRS optimally reduced the inflammatory response and the occurrence of sepsis, thereby improving the prognosis.

According to the variation in the number of MDSCs in the spleen after different fluid resuscitations, the HRS group optimally reduced the immune-mediated inflammation in the rat model of hemorrhagic shock compared with the LCR and LRS groups, and the prognosis was improved. Thus, HRS may be the ideal resuscitation fluid. Since the sample size in the present study was small, further confirmation is needed with larger-sample-size experiments.

\section{Conflicts of interest}

The authors declare no conflict of interest.

\section{ACKNOWLEDGMENTS}

Research supported by the Natural Science Fund Project in the Anhui Province Department of Education (\#KJ2012Z258).

\section{REFERENCES}

Cheng Q, Yang G, Ma J, Li J, et al. (2014). Effects of different types of fluid resuscitation on hepatic mitochondria and apoptosis. Exp. Ther. Med. 7: 335-342.

Chiara O, Pelosi P, Brazzi L, Bottino N, et al. (2003). Resuscitation from hemorrhagic shock: experimental model comparing normal saline, dextran, and hypertonic saline solutions. Crit. Care Med. 31: 1915-1922. http://dx.doi. org/10.1097/01.CCM.0000074725.62991.42

Cuenca AG, Delano MJ, Kelly-Scumpia KM, Moreno C, et al. (2011). A paradoxical role for myeloid-derived suppressor cells in sepsis and trauma. Mol. Med. 17: 281-292. http://dx.doi.org/10.2119/molmed.2010.00178

Darcy CJ, Minigo G, Piera KA, Davis JS, et al. (2014). Neutrophils with myeloid derived suppressor function deplete arginine and constrain T cell function in septic shock patients. Crit. Care 18: 1-12. http://dx.doi.org/10.1186/cc14003

Delano MJ, Scumpia PO, Weinstein JS, Coco D, et al. (2007). MyD88-dependent expansion of an immature GR-1(+) $\mathrm{CD} 11 \mathrm{~b}(+)$ population induces T cell suppression and Th2 polarization in sepsis. J. Exp. Med. 204: 1463-1474. http:// dx.doi.org/10.1084/jem.20062602

Gao J, Zhao WX, Xue FS, Zhou LJ, et al. (2009). Effects of different resuscitation fluids on acute lung injury in a rat model of uncontrolled hemorrhagic shock and infection. J. Trauma 67: 1213-1219. http://dx.doi.org/10.1097/ TA.0b013e31818cc1e4

Gao J, Zhou L, Ge Y, Lin S, et al. (2013). Effects of different resuscitation fluids on pulmonary expression of aquaporin1 and aquaporin5 in a rat model of uncontrolled hemorrhagic shock and infection. PLoS One 8: e64390. http://dx.doi. org/10.1371/journal.pone. 0064390 
Junger WG, Rhind SG, Rizoli SB, Cuschieri J, et al. (2012). Resuscitation of traumatic hemorrhagic shock patients with hypertonic saline-without dextran-inhibits neutrophil and endothelial cell activation. Shock 38: 341-350. http:// dx.doi.org/10.1097/SHK.0b013e3182635aca

Kim JY, Hong YS, Choi SH, Yoon YH, et al. (2012). Effect of hypertonic saline on apoptosis of polymorphonuclear cells. J. Surg. Res. 178: 401-408. http://dx.doi.org/10.1016/j.jss.2012.01.055

Köstlin N, Kugel H, Spring B, Leiber A, et al. (2014). Granulocytic myeloid derived suppressor cells expand in human pregnancy and modulate T-cell responses. Eur. J. Immunol. 44: 2582-2591. http://dx.doi.org/10.1002/eji.201344200

Krystal G, Sly L, Antignano F, Ho V, et al. (2007). Re: the terminology issue for myeloid-derived suppressor cells. Cancer Res. 67: 3986. http://dx.doi.org/10.1158/0008-5472.CAN-07-0211

Lu YQ, Gu LH, Zhang Q, Jiang JK, et al. (2013). Hypertonic saline resuscitation contributes to early accumulation of circulating myeloid-derived suppressor cells in a rat model of hemorrhagic shock. Chin. Med. J. (Engl.) 126: 1317-1322.

Schneider CP, Schwacha MG and Chaudry IH (2006). Impact of sex and age on bone marrow immune responses in a murine model of trauma-hemorrhage. J. Appl. Physiol. 102: 113-121. http://dx.doi.org/10.1152/japplphysiol.00848.2006

Serafini P, Mgebroff S, Noonan K and Borrello I (2008). Myeloid-derived suppressor cells promote cross-tolerance in B-cell lymphoma by expanding regulatory T cells. Cancer Res. 68: 5439-5449. http://dx.doi.org/10.1158/0008-5472. CAN-07-6621

Velasco IT, Pontieri V, Rocha e Silva M, Jr. and Lopes OU (1980). Hyperosmotic NaCl and severe hemorrhagic shock. Am. J. Physiol. 239: H664-H673.

Villarroel JP, Guan Y, Werlin E, Selak MA, et al. (2013). Hemorrhagic shock and resuscitation are associated with peripheral blood mononuclear cell mitochondrial dysfunction and immunosuppression. J. Trauma Acute Care Surg. 75: 24-31. http://dx.doi.org/10.1097/TA.0b013e3182988b1f

Yang H, Bi Y, Han F, Lu Y, et al. (2015). Myeloid-derived suppressor cells in immunity and autoimmunity. Expert Rev. Clin. Immunol. 11: 911-919. http://dx.doi.org/10.1586/1744666X.2015.1052794

Yao T, Lu W, Zhu J, Jin X, et al. (2015). Role of CD11b+Gr-1+ myeloid cells in AGEs-induced myocardial injury in a mice model of acute myocardial infarction. Int. J. Clin. Exp. Pathol. 8: 3238-3249. 